\title{
ESOPHAGEAL TRACHEOBRONCHOPLASTY FOR DISEASES OF THE CENTRAL AIRWAY
}

Hiroshi Niwa, MD

Akira Masaoka, MD

Yosuke Yamakawa, MD

Fujio Hara, MD

Kaoru Kondo, MD

Ichirou Fukai, MD

Masanobu Kiriyama, MD

Satoshi Kondo, MD
Three infants with congenital tracheal stenosis and three adults with various diseases of the central airway underwent esophageal tracheobronchoplasty to repair long-segment stenoses and defects. The primary operative goal was enlargement of the stenosis $(n=4)$, repair of the defect $(n=$ 1 ), or both ( $n=1)$. Cardiopulmonary support was required in two cases. All three infants were operated on for generalized congenital tracheal stenoses. There was one postoperative death on the fifth day. Another infant died of pneumonia 3 months after operation. Tracheal patency was excellent in two infants. One infant is well without symptoms 6 years after the operation, although balloon dilation was required three times during the first postoperative year. In the three adult patients, the primary diseases were congenital tracheal stenosis, iatrogenic injury associated with relapsing polychondritis, and malignant mediastinal tumor involving the trachea. All lesions involved both the trachea and main stem bronchi. Postoperative airway patency was excellent in all three adults, although expandable metallic stents had to be inserted in one patient. Postoperative pulmonary function was improved, particularly forced expiratory volume in 1 second and peak expiratory flow rate. Although the postoperative mortality rate was still high, especially among the infants, and prolonged postoperative ventilatory support was required for five of the six patients, long-term patency and postoperative pulmonary functional improvement are encouraging. (J Thorac Cardiovasc Surg 1996;112:124-9)
T racheoplasty with the esophageal wall for complete congenital tracheal stenosis was initially described by Ein and coworkers ${ }^{1}$ in 1982 . Subsequently, Loeff and colleagues ${ }^{2}$ and Sasaki and associates $^{3}$ also reported use of this technique to treat patients with congenital tracheal stenosis. We employed this technique to treat not only congenital stenosis but also adult tracheal long-segment stenoses and defects. We previously reported the treatment of a tracheobronchial iatrogenic injury with this method ${ }^{4}$ and have also used it in a patient with a malignant mediastinal tumor involving the trachea. Stenoses of the main stem bronchi extending from the trachea and defects in the membranous

From the Second Department of Surgery, Nagoya City University, Medical School, Nagoya, Japan.

Received for publication Dec. 16, 1994; revisions requested Feb. 20, 1995; revisions received Nov. 2, 1995; accepted for publication Nov, 7, 1995.

Address for reprints: Hiroshi Niwa, MD, Second Department of Surgery, Nagoya City University, Medical School, Mizuhocho, Mizuho-ku, Nagoya, 467, Japan.

Copyright (c) 1996 by Mosby-Year Book, Inc.

$0022-5223 / 96 \$ 5.00+0 \quad \mathbf{1 2 / 1 / 7 0 5 3 9}$ portion of the central airway can thus be treated by tracheoplasty with the esophageal wall. We therefore propose that the technique be termed "esophageal tracheobronchoplasty." Because most patients who underwent this operation were infants, postoperative pulmonary function tests have not been performed. Improvement in pulmonary function was demonstrated in the adult patients after esophageal tracheobronchoplasty in this study.

\section{Patients and methods}

Patients. Six patients (four male and two female) underwent esophageal tracheobronchoplasty. Three were infants with congenital tracheal stenosis and three were adults with various diseases. Because the cases of patients 1,2 , and 6 have already been reported elsewhere, ${ }^{3,4}$ details regarding these patients are not described here.

Surgical technique. The operative technique differed slightly from that described by Ein and coworkers ${ }^{1}$ in 1982. The differences included resection of the cartilage and an approach through a right thoracotomy, which facilitated treatment of lesions extending to the main stem bronchi. After induction of anesthesia, the patient was ventilated through an orotracheal or tracheostomy tube. The trachea and main stem bronchi were mobilized through a right thoracotomy. Circumferential mobiliza- 
tion of the esophagus was not performed, to preserve the esophageal blood supply. The posterior membranous trachea and main stem bronchi with the involved stenosis were incised at the midline (Fig. 1, A). The involved membranous trachea was resected in one patient with a tumor. A portion of the cartilaginous trachea was also resected longitudinally if necessary. If transverse resection of the cartilage was required, anastomosis between the remaining cartilage was performed. At that point in the operation, an endobronchial tube was inserted into the left main stem bronchus from the operative field and left single-lung ventilation was initiated. Closure was first performed between the left side of the incised trachea and the anterior esophageal wall with running absorbable suture (Fig. 1, B). After completion of the left-sided anastomosis, the endotracheal tube was used to expand the lumen of the affected trachea to the appropriate size. The right edge of the incised trachea was then sutured to the anterior esophageal wall from cephalad to caudad. The endobronchial tube was removed when that portion of the anastomosis was nearly complete. Ventilation was accomplished through the endotracheal tube, and the anastomosis was completed (Fig. 1, C).

\section{Results}

Esophageal tracheobronchoplasty was performed in six patients. The primary goals of tracheobronchoplasty were to enlarge a stenosis $(n=4)$, to repair a defect after resection of the membranous portion of the trachea and main stem bronchus ( $n=$ $1)$, or both $(n=1)$.

In all three infants, the operations were performed to correct generalized congenital tracheal stenoses (Table I). Aberrant origin of the left pulmonary artery from the right pulmonary artery (pulmonary artery sling) was present in all three patients and tetralogy of Fallot was present in one infant. All esophageal tracheobronchoplasties were performed through a right thoracotomy. In the case of the infant with tetralogy of Fallot (patient 3), the right thoracotomy was performed immediately after a Blalock operation had been completed through a median sternotomy with cardiopulmonary support. The entire length of the thoracic trachea was repaired in all infants. An anomalous left pulmonary artery (pulmonary artery sling) was treated by pulmonary arteriopexy before esophageal tracheobronchoplasty in patient 1 . No surgical countermeasures were considered necessary for the other two infants. There was one early postoperative death. Patient 3 died of renal and respiratory failure 5 days after the operation. The right main stem bronchus was compressed by the anomalous left pulmonary artery (pulmonary artery sling), although at the time of the operation the sling had been determined not to affect the airway. The two other infants required endotracheal intubation and ventilatory support for 3 months. Patient 1 underwent two operations (pulmonary arteriopexy and tracheoplasty with pericardium) before esophageal tracheobronchoplasty. This infant died of pneumonia 3 months after esophageal tracheobronchoplasty, presumably as a result of interstitial emphysema and malacia of the main stem or distal bronchi, which developed as a result of prolonged high-pressure ventilation during the 5 months before esophageal tracheobronchoplasty. Airway patency was excellent in two infants (including patient 1). Patient 2 is well without symptoms at 6 years after the operation, although balloon dilation was required three times during the first postoperative year.

In the three adult patients, the primary diseases were congenital tracheal stenosis, iatrogenic injury associated with relapsing polychondritis, and malignant mediastinal tumor (malignant epithelioid schwannoma) involving the trachea (Table II). All of the various lesions were segmental, affecting 5 to $9 \mathrm{~cm}$ of the central airway. The right main stem bronchus was involved in two patients and the left main stem bronchus was involved in one patient. The operations were performed through a right thoracotomy. Almost the entire length of the trachea and right main stem bronchus were enlarged by esophageal tracheobronchoplasty in patient 4. Endotracheal intubation with continuous positive airway pressure was required for 2 weeks after operation. Preoperative and postoperative computer tomographic (Fig. 2) and bronchoscopic (Fig. 3) examinations demonstrated marked dilation of tracheal stenosis. Postoperative bronchoscopy showed epithelialization over the esophageal wall (Fig. 3, B). The malignant epithelioid schwannoma (patient 5) involved not only the posterior membranous trachea and right main stem bronchus but also the cartilaginous portion of the right main stem bronchus. An $8 \mathrm{~cm}$ length of the membranous portion was resected, and the involved cartilage was removed by wedge resection. The subsequent defect in the cartilage, which included two rings, was primarily sutured with absorbable material. Esophageal tracheobronchoplasty was then performed to repair the defect. No ventilatory support was required after this operation. Postoperative radiotherapy was performed because of the involved margins. The patient died of systemic metastases without local recurrence.

Oxygenation was maintained in patient 6 with percutaneous cardiopulmonary support from the 
A
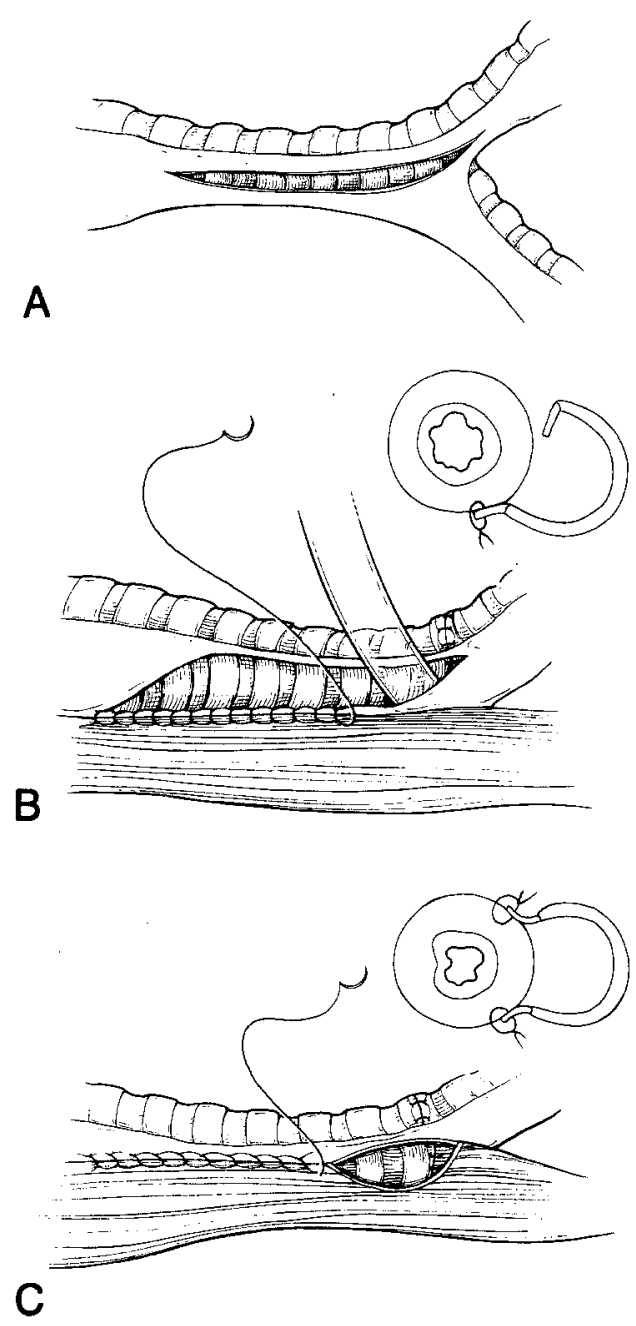

Fig. 1. A, After the trachea and main stem bronchi were mobilized, the posterior membranous portions of the involved segment were incised at the midline. B, With left single-lung ventilation, anastomosis with running absorbable suture was initiated between the left side of the incised trachea and the anterior esophageal wall. If transverse cartilaginous resection was required, anastomosis between the remaining cartilage was performed before this point. C, After completion of the left-sided anastomosis, the endotracheal tube was used to expand the lumen of the affected trachea to the appropriate size. The right edge of the incised trachea was then sutured to the anterior esophageal wall, beginning from the cephalic end. The endobronchial tube was removed when the anastomosis was nearly completed. Ventilation was then accomplished through the endotracheal tube, and the anastomosis was completed. (Crosssections present a caudad-cranial view.)

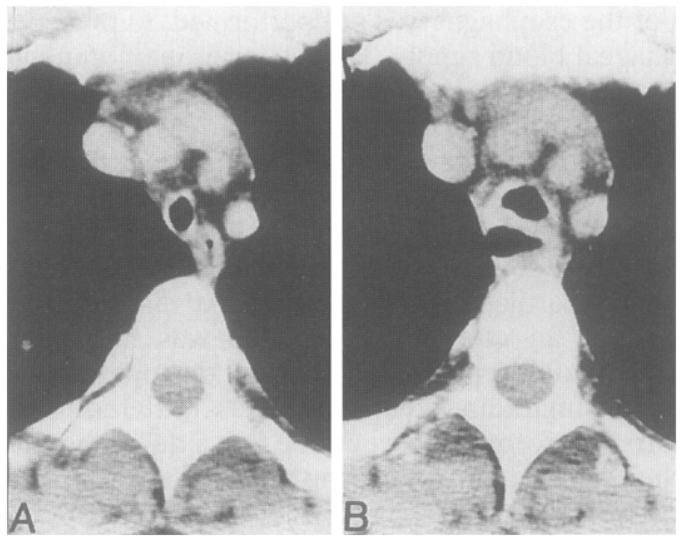

Fig. 2. A, Preoperative computed tomographic scan. B, Postoperative computer tomographic scan obtained 1 years after esophageal tracheobronchoplasty demonstrates marked improvement of tracheal stenosis.
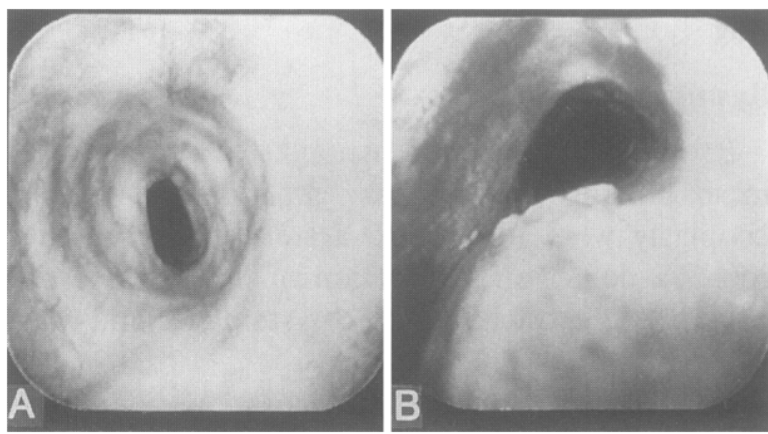

Fig. 3. A, Preoperative bronchoscopic photograph shows tracheal stenosis with complete ring. B, Postoperative bronchoscopic photograph 2 months after esophageal tracheobronchoplasty shows dramatic enlargement of trachea. Epithelialization over the esophageal wall is almost complete behind the protrusion at the cephalad portion of the anastomosis.

time of tracheobronchial disruption until stabilization 1 day after the operation. The posterior membranous trachea and left main stem bronchus sustained a $5 \mathrm{~cm}$ longitudinal tear across the carina. There were no difficulties in the repair of the left main stem bronchus. The injury was repaired and the stenosis surrounding the trauma was enlarged at the same time. Ventilatory support was continued until 3 weeks after the operation, when expandable metallic stents were inserted. Patency of the airway was excellent in all three adults.

Pulmonary function tests were performed in the three adult patients with primary diseases of congenital tracheal stenosis (patient 4), malignant me- 
Table I. Infants with congenital tracheal stenosis

\begin{tabular}{cllcllll}
\hline No. & Age & Sex & $\begin{array}{c}\text { Lesion } \\
\text { length }\end{array}$ & $\begin{array}{c}\text { Other } \\
\text { abnormality }\end{array}$ & $\begin{array}{c}\text { Postop. airway } \\
\text { support }\end{array}$ & $\begin{array}{c}\text { Airway } \\
\text { patency }\end{array}$ & \multicolumn{1}{c}{ Outcome } \\
\hline 1 & $7 \mathrm{mo}$ & $\mathrm{M}$ & ET & PAS & EI (3 mo) & Excellent & Died of pneumonia (3 mo) \\
2 & $8 \mathrm{mo}$ & F & ET & PAS & EI (3 mo), BD & Excellent & Well (6 yr) \\
3 & 2 mo & M & ET & PAS, TOF & EI (5 days) & Fair & Died of RRF (5 days)
\end{tabular}

$B D$, Balloon dilatation; $E I$, endotracheal intubation; $E T$, entire trachea; $P A S$, pulmonary artery sling; $R R F$, renal and respiratory failure; $T O F$, tetralogy of Fallot.

Table II. Adult patients with various diseases of the central airway

\begin{tabular}{clllllll}
\hline No. & Age & Sex & Lesion length & $\begin{array}{c}\text { Primary } \\
\text { disease }\end{array}$ & $\begin{array}{c}\text { Postop. airway } \\
\text { support }\end{array}$ & $\begin{array}{c}\text { Airway } \\
\text { patency }\end{array}$ & Outcome \\
\hline 4 & $35 \mathrm{yr}$ & F & TB $(\mathrm{rt}), 9 \mathrm{~cm}$ & CTS & EI (2 wk) & Excellent & Well (3 yr) \\
5 & $27 \mathrm{yr}$ & M & TB $(\mathrm{rt}), 8 \mathrm{~cm}$ & MT & None & Excellent & Died of SM (7 mo) \\
6 & $39 \mathrm{yr}$ & M & TB $(\mathrm{lt}), 5 \mathrm{~cm}$ & II, RP & EI (3 wk) & Excellent & Well (16 mo) \\
\hline
\end{tabular}

$C T S$, Congenital tracheal stenosis; $E I$, endotracheal intubation; $E M S$, expandable metallic stent; $I I$, iatrogenic injury; $M T$, mediastinal tumor; $R P$, relapsing polychondritis; $S M$, systemic metastases; $S S$, silicon stent left at operation; $T B$, trachea and main stem bronchus.

diastinal tumor (patient 5), and iatrogenic tracheal injury associated with relapsing polychondritis (patient 6; Table III). Although the postoperative vital capacity was slightly decreased, forced expiratory volume in 1 second, peak expiratory flow rate, and flow rate at $50 \%$ volume were markedly improved in all patients (Fig. 4). Patients with previous symptoms, including exertional dyspnea and palpitations, showed remarkable improvement. None of the patients, including the one infant survivor, have evidence of respiratory compromise. One patient reported discomfort with swallowing, which resolved within 6 months. Esophagography demonstrated no stenosis or dislocation of the esophagus after operation in all of the adults.

\section{Discussion}

Although serial dilations ${ }^{5}$ or resection ${ }^{6}$ with primary anastomosis may be sufficient to treat localized lesions of the trachea, the surgical treatment of long-segment stenoses or defects is more challenging. The therapy is further complicated when the lesion extends to the main stem bronchi. Since Ein and coworkers ${ }^{1}$ employed the esophageal tracheoplasty only to treat congenital tracheal stenosis, few authors $^{2,3}$ have used this method. We applied this technique to other diseases, including tracheal injury associated with relapsing polychondritis and a malignant mediastinal tumor involving the trachea. Both long-segment stenoses and defects were treatable by tracheobronchoplasty. A main stem bronchial lesion could also be repaired with this technique. Our experience is worthwhile because it extends previous anecdotal reports. ${ }^{1-3}$
Because the surgical treatment of congenital tracheal stenosis has presented such a challenge, a variety of isolated autografting techniques have been described that use either pericardium, ${ }^{7,8}$ periosteum, ${ }^{2}$ or costal cartilage. ${ }^{9,10}$ Necrosis $^{7,10}$ and restenosis ${ }^{10}$ with subsequent shrinkage of isolated grafts have been reported, however, as a result of the poor blood supply to the anastomosis. Pericardium has not been shown to provide sufficient structural rigidity to prevent tracheal narrowing, even when used with periosteum as a composite graft. ${ }^{11}$ In our experience, the pericardium is not thick enough to tolerate high-pressure ventilation. ${ }^{3}$ Slide tracheoplasty ${ }^{12}, 13$ is another innovative option for funnel-shaped stenosis.

We employed the esophageal tracheobronchoplasty procedure for the following reasons: (1) Because native esophagus is used, the operation does not result in ischemic complications of the graft material. (2) Generalized stenosis can be repaired. (3) Cardiopulmonary bypass can be avoided if an associated cardiac operation is not performed. (4) Normal growth can be expected after operation. One of the causes of difficulty in the establishment of adequate patency in the infant may be associated vascular anomaly. Idriss and associates ${ }^{8}$ reported the case of a patient who required a tracheostomy for a prolonged period because of a right aortic arch. One of the reasons for respiratory failure in patient 3 was narrowing of the right main stem bronchus as the result of an anomalous left pulmonary artery (pulmonary artery sling). Although division of a vascular ring or sling will not eliminate significant tracheal narrowing, removal of the com- 
Table III. Pulmonary function before and after esophageal tracheobronchoplasty

\begin{tabular}{|c|c|c|c|c|c|c|}
\hline & \multicolumn{2}{|c|}{ Patient 4} & \multicolumn{2}{|c|}{ Patient 5} & \multicolumn{2}{|c|}{ Patient 6} \\
\hline & Before & $\begin{array}{c}\text { After } \\
\left(25 \mathrm{mo}^{*}\right)\end{array}$ & Before & $\begin{array}{c}\text { After } \\
\left(3 m o^{*}\right)\end{array}$ & Before & $\begin{array}{c}\text { After } \\
\left(3 \mathrm{mo}^{*}\right)\end{array}$ \\
\hline $\mathrm{VC}(\mathrm{L})$ & 3.28 & 3.11 & 3.70 & 2.78 & 3.04 & 2.14 \\
\hline$\% \mathrm{VC}(\%)$ & 115.0 & 110.0 & 88.0 & 66.0 & 79.6 & 56.0 \\
\hline $\mathrm{FEV}_{1}(\mathrm{~L})$ & 1.14 & 1.78 & 2.2 & 2.35 & 0.46 & 1.32 \\
\hline $\mathrm{FEV}_{1} \%(\%)$ & 35.0 & 58.0 & 63.0 & 83.0 & 17.3 & 56.4 \\
\hline PEFR (L/sec) & 1.88 & 2.94 & 3.40 & 7.64 & 1.28 & 1.89 \\
\hline $\mathrm{V}_{25}(\mathrm{~L} / \mathrm{sec})$ & 0.30 & 0.56 & 0.90 & 0.62 & 0.23 & 0.91 \\
\hline $\mathrm{V}_{50}(\mathrm{~L} / \mathrm{sec})$ & 0.58 & 1.56 & 1.90 & 3.64 & 0.32 & 1.48 \\
\hline
\end{tabular}

$F E V_{1}$, Forced expiratory volume in 1 second; $F E V_{1} \%, \mathrm{FEV}_{1} / \mathrm{VC}(\%) ; P E F R$, peak expiratory flow rate; $V C$, Vital capacity; \%VC, percentage of predicted vital capacity; $V_{25}$, flow rate at $25 \%$ volume; $V_{50}$, flow rate at $50 \%$ volume.

*Duration after esophageal tracheobronchoplasty.
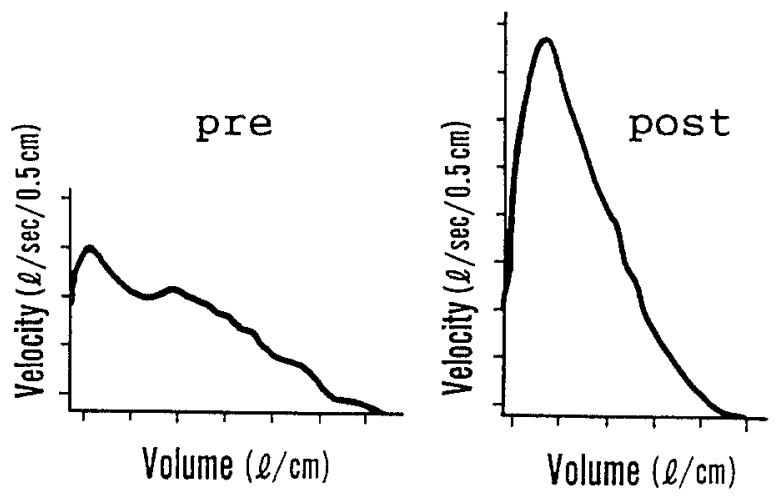

Fig. 4. Maximum expiratory flow-volume curves obtained prior to the operation (pre), and 3 months after tracheobronchoplasty (post) in patient 5 . Note the significant postoperative improvement.

pression by the vascular anomaly is essential. Pulmonary arteriopexy was successfully performed in Patient 1. No compression was observed at the second and third operations (tracheoplasty with pericardium followed by tracheobronchoplasty).

Esophageal tracheobronchoplasty can also be used to treat various diseases associated with longsegment tracheal stenosis in adults. The most common causes of long-segment tracheal stenoses are tuberculosis, syphilis, relapsing polychondritis, congenital stenosis, and trauma. Respiratory tract involvement is a significant cause of mortality among patients with relapsing polychondritis. Because the disease produces diffuse narrowing of the central airway, including the entire trachea and bronchus, administration of steroids and immunosuppressive drugs has been the preferred treatment. ${ }^{14}$ Trache- ostomy and stenting with silicon T-tubes or TYtubes has been employed in some patients with severe respiratory distress. ${ }^{15}$ Expandable metallic stents have also been shown to be useful in maintaining airway patency in patients with this disease. ${ }^{16}$ Unless airway patency is achieved with these stents, prolonged ventilation is usually required; this often results in infectious complications that exacerbate the condition. Airway dilation is therefore recommended before stenting.

Longitudinal injuries of the membranous trachea have been repaired with pericardium, ${ }^{17}$ intercostal muscles, ${ }^{18}$ and lung tissue. ${ }^{19}$ In patient 6 , the injury occurred 5 days before operation. The patient had received steroids. The risk of infection was therefore high. The abundant blood supply to the esophageal wall made it superior to an isolated graft for this repair. Furthermore, esophageal tracheobronchoplasty allowed repair of the accidental tracheobronchial disruption and the primary stenosis.

Another application of esophageal tracheobronchoplasty is the repair of a defect created by resection of the membranous portion of the central airway. Partial resection of the trachea is an appropriate treatment for benign tumors and secondary involvement from extrinsic tumors. Surgical removal of these neoplasms and trauma often result in longsegment defects in the membranous portion. The defect can easily be repaired with esophageal tracheobronchoplasty. If transverse cartilaginous resection is required, a primary repair should be performed first. Complete resection of rings can also be performed.

Lesions around the carina are associated with significant morbidity and mortality. ${ }^{7}$ The intrathoracic trachea, carina, and left and right main stem bronchi can be accessed through a right thoracotomy. Right 
thoracotomy provides a better approach to these lesions than does median sternotomy. A cervical incision and median sternotomy is, however, required for treatment of lesions extending to the subglottis.

Prolonged endotracheal intubation for airway support was required in four cases for at least 2 weeks before the airway became rigid. When adequate airway patency was provided, spontaneous breathing could be started with the assistance of continuous positive airway pressure. The airways were stabilized after resolution of the edema in the esophageal wall and trachea. Loeff and colleagues ${ }^{2}$ have reported the case of a patient in whom adequate ventilation could not be maintained, presumably because of collapse of the esophageal wall into the tracheal lumen. A new posterior wall made too wide with esophageal tissue may easily collapse. A stent can be applied to prevent the obstruction. Tracheal patency can be maintained by advancement of the endotracheal tube after operation. Internal stents are left in the main stem bronchi when the airway is easily compressed at operation. A silicon stent was sutured to the left main stem bronchus in patient 6 . This stent was later removed bronchoscopically when expandable metallic stents were inserted. Metallic stents should not be used in infants because of the possibility of tracheoesophageal fistulas. ${ }^{2}$ Material and size must be carefully considered when stents are required. Growth of the new trachea provided adequate patency for patient $2 .^{3}$ This is encouraging evidence that esophageal tracheobronchoplasty can be used in infants. Epithelialization of the esophageal wall is usually achieved within 1 month, with apparent stability after 3 months.

Successful enlargement of the trachea with esophageal tracheobronchoplasty resulted in improvement in pulmonary function. Increases in forced expiratory volume in 1 second and peak expiratory flow rate were characteristic of relief of the stenosis. A marked increase in peak expiratory flow rate resulted from rigid patency of the central airway. Although the postoperative mortality rate was still high, especially among infants, and prolonged postoperative ventilatory support was required in some cases, the postoperative pulmonary functional improvement encourages use of esophageal tracheobronchoplasty in the treatment of congenital tracheal stenoses, as well as other tracheobronchial diseases of the central airway.

\section{REFERENCES}

1. Ein SH, Friedberg J, Williams WG, Rearon B, Barker GA, Mancer K. Tracheoplasty: a new operation for complete congenital tracheal stenosis. J Pediatr Surg 1982;17:872-8.

2. Loeff DS, Filler RM, Vinograd I, et al. Congenital tracheal stenosis: a review of 22 patients from 1965 to 1987. J Pediatr Surg 1988;23:744-8.

3. Sasaki S, Hara F, Oowa T, Eguchi T, Masaoka A. Esophageal tracheoplasty for congenital tracheal stenosis. J Pediatr Surg 1992;27:645-9.

4. Niwa H, Masaoka A, Yamakawa Y, Fukai I, Kiriyama M, Shindou J. Esophageal tracheobronchoplasty for membranous laceration caused by insertion of a Dumon stent: maintenance of oxygenation by PCPS. Eur J Thorac Cardiovasc Surg 1995;9:213-5.

5. Hebra A, Powell DD, Smith CD, Othersen HB Jr. Balloon tracheoplasty in children: results of a 15 -year experience. $\mathrm{J}$ Pediatr Surg 1991;26:957-61.

6. Kato R, Kakizaki T, Hangai N, et al. Bronchoplastic procedures for tuberculous bronchial stenosis. J Thorac Cardiovasc Surg 1993;106:1118-21.

7. Dunham ME, Holinger LD, Backer CL, Mavroudis C. Management of severe congenital tracheal stenosis. Ann Otol Rhinol Laryngol 1994;103:351-6.

8. Idriss FS, Delson SY, Ilbawi MN, Gerson CR, Tucker GF, Holinger L. Tracheoplasty with pericardial patch for extensive tracheal stenosis in infants and children. J Thorac Cardiovase Surg 1984;88:527-36.

9. Kimura K, Mukohara N, Tsugawa C, et al. Tracheoplasty for congenital stenosis of the entire trachea. J Pediatr Surg $1982 ; 17: 869-71$.

10. Tsugawa C, Kimura K, Muraji T, Nishijima E, Matsumoto Y, Murata $\mathrm{H}$. Congenital stenosis involving a long segment of the trachea: further experience in reconstructive surgery. J Pediatr Surg 1988;23:471-5.

11. Dykes EH, Bahoric A, Smith C, Kent G, Filler RM. Reduced tracheal growth after reconstruction with pericardium. J Pediatr Surg 1990;25:25-9.

12. Tsang V, Murday A, Gillbe C, Goldstraw P. Slide tracheoplasty for congenital funnel-shaped tracheal stenosis. Ann Thorac Surg 1989;48:632-5.

13. Grillo HC. Slide tracheoplasty for long-segment congenital tracheal stenosis. Ann Thorac Surg 1994;58:610-2.

14. Clark LJ, Wakeel RA, Ormerod AD. Relapsing polychondritis: two cases with tracheal stenosis and inner ear involvement. J Laryngol Otol 1992;106:841-4.

15. Grillo HC. Management of non-neoplastic diseases of the trachea. In: Shields TW, editor. General thoracic surgery. Malvern: Williams \& Wilkins, 1994:815-27.

16. Dunne JA, Sabanathan S. Use of metallic stents in relapsing polychondritis. Chest 1994;105:864-7.

17. Gorenstein LA, Abel JG, Patterson GA. Pericardial repair of a tracheal laceration during transhiatal esophagectomy. Ann Thorac Surg 1992;54:784-6.

18. Bahn CH, Vitikainen KJ. Repair of tracheal injuries. Am J Surg 1981;141:528-30.

19. Sarfati E, Jacob L, Servant JM. Tracheobronchial necrosis after caustic ingestion. J Thorac Cardiovasc Surg 1992;103: 412-3. 